\title{
Sistem Pendukung Keputusan Memilih Tiket Pesawat Dengan Menggunakan Metode AHP
}

\author{
Fikri Maulana $^{1}$, Dwiny Meidelfi ${ }^{2}$ \\ 1 e-mail: maulsana25@gmail.com ${ }^{2}$ dwinymeidel@pnp.ac.id \\ ${ }^{1}$ Prodi D4 Teknologi Rekayasa Perangkat Lunak Politeknik Negeri Padang, \\ ${ }^{2}$ Jurusan Teknologi Informasi Politeknik Negeri Padang,
}

Abstract - The choice of many airlines makes people who want to travel by plane a little confusion to determine choices, needs and desires. This can be overcome by using a Decision Support System that uses the AHP method to process data. The results obtained from the system can be an alternative consideration that can be chosen so that the criteria desired by customers are met.

Intisari- Pilihan maskapai penerbangan yang banyak membuat orang yang ingin bepergian menggunakan pesawat sedikit kebingungan menentukan pilihan, kebutuhan dan keinginan. Hal ini bisa diatasi dengan menggunakan Sistem Pendukung Keputusan yang menggunakan metode AHP untuk mengolah data. Hasil yang didapat dari sistem dapat menjadi pertimbangan alternatif yang dapat dipilih sehingga kriteria yang diinginkan pelanggan terpenuhi.

Kata Kunci-SPK, sistem pendukung keputusan, AHP, pesawat, SPK pesawat.

\section{PENDAHULUAN}

Jumlah maskapai di Indonesia mengalami pertumbuhan yang signifikan. Berdasarkan [1],jumlah penumpang di bandara Soekarno Hatta pada tahun 2019, hingga oktober 2019 sebanyak 15.616.108 penumpang. Jumlah tersebut menandakan industri penerbangan di indonesia sangat bagus.

Beragamnya maskapai penerbangan saat ini membuat calon penumpang kebingungan memilih maskapai yang menawarkan layanan dan fasilitas yang berbeda-beda. Harga tiket saat ini juga menentukan pilihan calon penumpang untuk memutuskan membeli tiket pesawat.

Pemilihan maskapai terbaik yang dapat memenuhi kebutuhan dan keinginan calon penumpang dapat menggunakan SPK yang membantu untuk menentukan keputusan terbaik. Dengan metode Analytical Hierarchy Process (AHP), digunakan untuk menyelesaikan masalah. Kelebihan AHP dapat menghitung validitas sampai batas toleransi sebagai kriteria dan alternatif yang dipilih calon penumpang. Juga AHP dapat memperhitungkan daya tahan output analisis sensitivitas pengambilan keputusan.

\section{TUJUAN PENELITIAN}

Tujuan perancangan sistem ini adalah menghasilkan sistem pemilihan maskapai penerbangan menggunakan metode Analytical Hierarchy Process (AHP).

\section{BATASAN MASALAH}

Untuk memperjelas pembahasan dan tujuan penelitian dapat tercapai, maka diperlukan pembatasan masalah. Batasan-batasan masalah yang dimaksud yaitu:

1. Kriteria yang digunakan untuk pemilihan maskapai yaitu harga, layanan, fasilitas, komitmen.

2. Metode yang dipakai pada artikel ini adalah metode Analytical Hierarchy Process (AHP).

\section{SISTEM PENDUKUNG KEPUTUSAN}

SPK adalah sistem yang memberi alternative keputusan yang membantu user dalam memilih keputusan yang akan diambil oleh user. Keputusan akhir diambil dari hasil proses pemilihan yang berasal dari alternative yang ada, untuk mendapatkan keputusan yang terbaik [2]. 


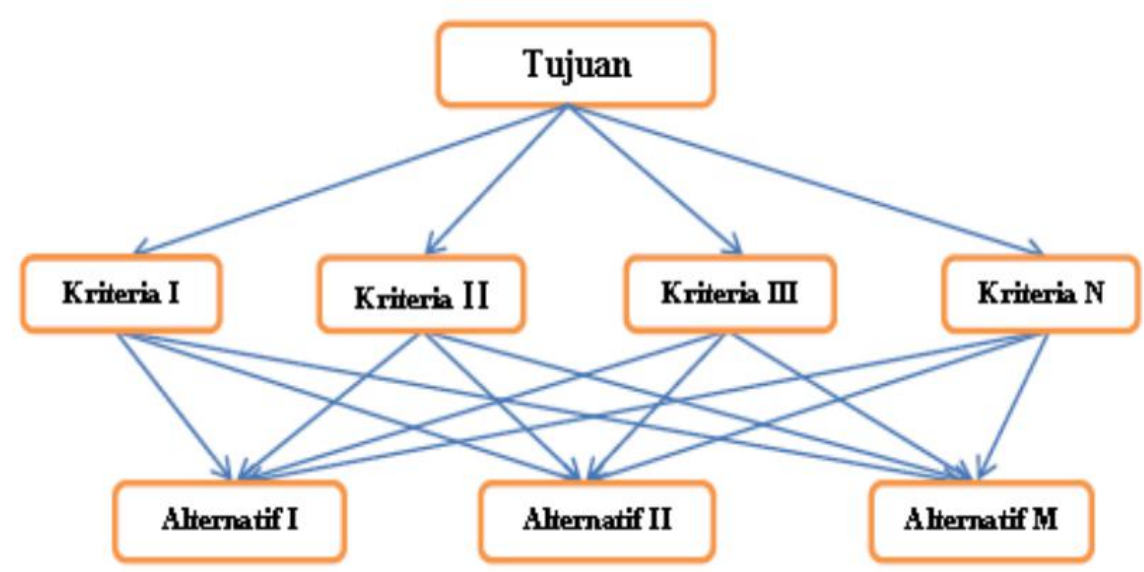

GAMBAR 1 STRUKTUR HIERARKI[3]

TABEL 1 SKALA PENILAIAN PERBANDINGAN BERPASANGAN[3]

\begin{tabular}{|c|c|c|}
\hline $\begin{array}{l}\text { Tingkat } \\
\text { Kepentingan }\end{array}$ & Definisi & Keterangan \\
\hline 1 & $\begin{array}{l}\text { Sama } \\
\text { Pentingnya }\end{array}$ & $\begin{array}{l}\text { Kedua elemen mempunyai } \\
\text { pengaruh yang sama. }\end{array}$ \\
\hline 3 & $\begin{array}{l}\text { Agak lebih } \\
\text { penting yang } \\
\text { satu atas } \\
\text { lainnya }\end{array}$ & $\begin{array}{l}\text { Pengalaman dan penilaian } \\
\text { sangat memihak satu elemen } \\
\text { dibandingkan dengan } \\
\text { pasangannya. }\end{array}$ \\
\hline 5 & cukup penting & $\begin{array}{l}\text { Pengalaman dan keputusan } \\
\text { menunjukkan kesukaan atas } \\
\text { satu aktifitas lebih dari yang } \\
\text { lain }\end{array}$ \\
\hline 7 & Sangat penting & $\begin{array}{l}\text { Pengalaman dan keputusan } \\
\text { menunjukkan kesukaan yang } \\
\text { kuat atas satu aktifitas lebih } \\
\text { dari yang lain }\end{array}$ \\
\hline 9 & $\begin{array}{l}\text { Mutlak lebih } \\
\text { penting }\end{array}$ & $\begin{array}{l}\text { Satu elemen mutlak lebih } \\
\text { disukai dibandingkan dengan } \\
\text { pasangannya, pada tingkat } \\
\text { keyakinan tertinggi. }\end{array}$ \\
\hline $2,4,6,8$ & $\begin{array}{l}\text { Nilai tengah } \\
\text { diantara dua } \\
\text { nilai berdekatan }\end{array}$ & Bila kompromi dibutuhkan \\
\hline
\end{tabular}

Menurut [4] langkah-langkah dalam membuat keputusan yaitu, (1) Identifikasi masalah, (2) Pemilihan metode pemecahan masalah, (3) Pengumpulan data, (4) mengimplementasikan model, (5) Mengevaluasi sisi positif tiap alternatif dan (6) melaksanakan solusi terpilih.

\section{ANALYTICAL HIERARCHY PROCESS}

Menurut [4] pada AHP terdapat beberapa prinsip yaitu

1. Membuat hierarki yaitu gambar 1 .

2. Kriteria dan alternatif.

3. menentukan prioritas merujuk pada tabel 1 . 
4. Konsistensi logis.

\section{ANALISA DATA SISTEM}

Berdasarkan survey yang dilakukan kepada beberapa masyarakat, kriteria yang digunakan untuk menentukan keputusan yaitu : Harga(HRG), Fasilitas(FAS), Ketepatan Waktu(KW), Merek(MRK).

VII. ANALISA PROSES RUMUS DAN LANGKAH-LANGKAH AHP

Pada kasus ini, terdapat 3 level yang menjadi faktor yang menentukan minat masyarakat terhadap penerbangan.

Level 1 : Tujuan

Besarnya minat masyarakat terhadap penerbangan.

Level 2 : Kriteria

Kriteria yang berasal dari input user, yaitu :

1. HRGHRG : Harga

2. FAS : Fasilitas

3. KW : Ketepatan Waktu

4. MRKMRK : Merek

Level 3 : Alternatif

1. GRDGRD : Garuda

2. CTLCTL : City Link

3. BTKBTK : Batik air

4. LN : Loin air

Pada gambar 2, diketahui minat masyarakat menjadi level tujuan, level kedua menjadi kriteria untuk mendapatkan level pertama dan level ketiga adalah alternatif dari level kriteria tersebut.

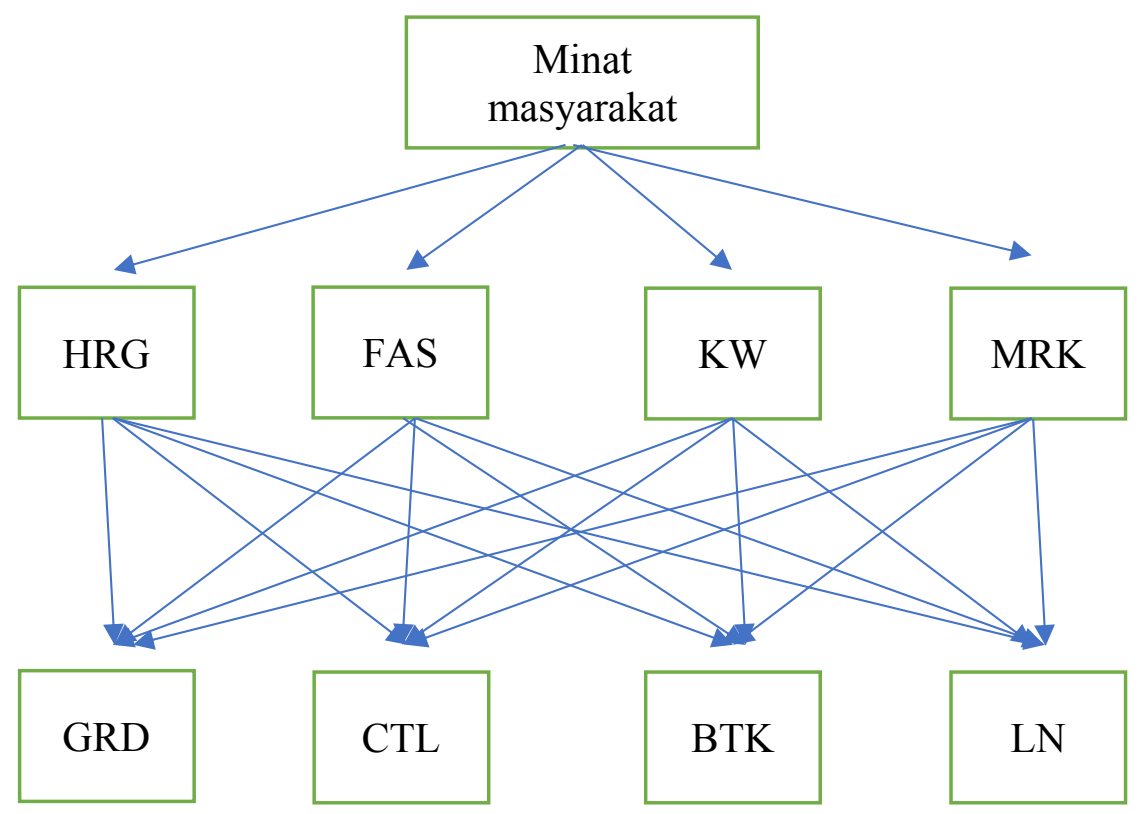

GAMBAR 2 HIERARKI

TABEL 2 MATRIK PERBANDINGAN ANTAR KRITERIA

\begin{tabular}{|c|cccc|}
\hline Kriteria & HRG & FAS & KW & MRK \\
\hline HRG & 1 & 3 & 5 & 7 \\
\hline FAS & 0,33 & 1 & 3 & 5 \\
\hline KW & 0,20 & 0,33 & 1 & 3 \\
\hline MRK & 0,14 & 0,2 & 0,33 & 1 \\
\hline Jumlah & 1,68 & 4,53 & 9,33 & 16 \\
\hline
\end{tabular}


TABel 3 Nilai EIGEN

\begin{tabular}{cccc} 
HRG & FAS & KW & MRK \\
\hline 0,60 & 0,66 & 0,54 & 0,44 \\
\hline 0,20 & 0,22 & 0,32 & 0,31 \\
\hline 0,12 & 0,07 & 0,11 & 0,19 \\
\hline 0,09 & 0,04 & 0,04 & 0,06 \\
\hline
\end{tabular}

TABEL 4 NORMALISASI NILAI EIGEN

$\begin{array}{cc}\text { Normalisasi } & \begin{array}{c}\text { Nilai } \\ \text { Eigen }\end{array} \\ 0,6+0,66+0,54+ & \\ 0,44 / 4 & 0,56 \\ 0,20+0,22+0,32+ & \\ & 0,31 / 4 \\ 0,12+ & 0,07+0,11+ \\ 0,19 / 4 & \\ 0,09+0,04+0,04+ & 0,12 \\ 0,06 / 4 & 0,06\end{array}$

Untuk menghitung nilai eigen digunakan rumus,,$\frac{\text { nilai bobot }}{\text { jumlah bobot }}$ nilai bobot dan jumlah bobot dapat dilihat di tabel 2, dan nilai eigen pada tabel 3. Kemudian nilai eigen di normalisasi sehingga menjadi nilai eigen tabel 4. Untuk mendapatkan nilai lamda maksimal tiap bari nilai eigen pada tabel 3 dikalikan dengan jumlah dari tiap kolom tabel 2.

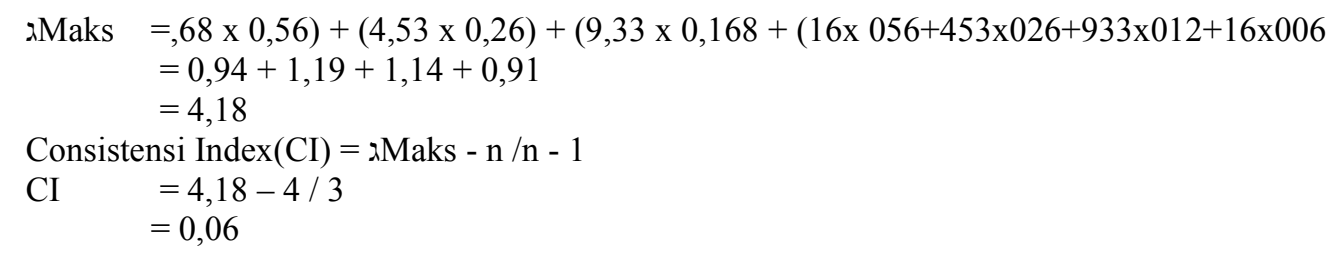

$$
\begin{aligned}
& \text { Untuk } \mathrm{n}=4, \mathrm{RI}=0,90 \\
& \begin{aligned}
\mathrm{CR} \quad & 0,06 / 0,90 \\
& =0,07
\end{aligned}
\end{aligned}
$$

Karena $\mathrm{CR}<0,1$ maka konsisten

Kriteria HRG memiliki nilai tertinggi 0,56

Kriteria FAS memiliki nilai tertinggi kedua 0,26

Kriteria KW memiliki nilai tertinggi ketiga 0,19

Kriteria MRK memiliki nilai tertinggi keempat 0,06 
TABEL 5 KONVERSI NILAI

\begin{tabular}{|c|c|}
\hline Konversi & $\begin{array}{l}\text { Nilai } \\
\text { Konversi }\end{array}$ \\
\hline$<1 j t$ & 7 \\
\hline $1-1,5 \mathrm{jt}$ & 5 \\
\hline$>1,5 \mathrm{jt}$ & 3 \\
\hline
\end{tabular}

TABEL 6 PERBANDINGAN MATRIK DENGAN ALTERNATIF HARGA

\begin{tabular}{|c|cccc|}
\hline Kriteria & GRD & CTL & BTK & LN \\
\hline GRD & 1 & 0,20 & 0,33 & 0,14 \\
\hline CTL & 5 & 1 & 3 & 0,50 \\
\hline BTK & 3 & 0,33 & 1 & 0,50 \\
\hline LN & 7 & 2 & 2 & 1 \\
\hline Jumlah & 16,00 & 3,53 & 6,33 & 2,14 \\
\hline
\end{tabular}

TABEL 7 PERBANDINGAN MATRIK DENGAN ALTERNATIF HARGA

\begin{tabular}{|cccc|c|}
\hline GRD & CTL & BTK & LN & $\begin{array}{c}\text { Nilai } \\
\text { Eigen }\end{array}$ \\
\hline 0,06 & 0,06 & 0,05 & 0,07 & 0,06 \\
\hline 0,31 & 0,28 & 0,47 & 0,23 & 0,33 \\
\hline 0,19 & 0,09 & 0,16 & 0,23 & 0,17 \\
\hline 0,44 & 0,57 & 0,32 & 0,47 & 0,45 \\
\hline
\end{tabular}

Pada tabel 5 harga tiket dibawah 1 juta menjadi 7, lalu diantara 1 juta sampai 1,5 juta menjadi 5 dan lebih dari 1,5 juta menjadi 3. Untuk mendapatkan nilai lamda maksimal, maka tiap kolom jumlah pada tabel 6 dikalikan dengan tiap baris nilai eigen kemudian hasil kali tersebut ditambahkan sehingga mendapatkan nilai lamda maksimal.

גMaks $=(16 \times 0,06)+(3,53 \times 0,33)+(6,33 \times 0,17)+(2,14 \times 0,45)$

$=0,95+1,15+1,07+0,96$

$=4,13$

Consistensi Index $(\mathrm{CI})=($ גMaks $-\mathrm{n}) /(\mathrm{n}-1)$

CI $=4,18-4 / 3$

$=0,04$

Untuk $\mathrm{n}=4, \mathrm{RI}=0,90$

$\mathrm{CR}=0,04 / 0,90$

$=0,05$

Karena $\mathrm{CR}<0,1$ maka konsisten

Alternatif LN memiliki nilai tertinggi 0,45

Alternatif CTL memiliki nilai tertinggi kedua 0,33

Alternatif BTK memiliki nilai tertinggi ketiga 0,17

Alternatif GRD memiliki nilai tertinggi keempat 0,06

Untuk mendapatkan nilai bobot prioritas global maka baris kriteria tabel 8 dikalikan dengan kolom nilai eigen pada tabel 4 . Untuk mencari minat masyarakat terhadap pembelian tiket pesawat maka dicari dengan mendapatkan bobot prioritas global. 
TABEL 8 NiLAI ALTERNATIF

\begin{tabular}{|ccccc|}
\hline Alternatif & HRG & FAS & WP & MRK \\
\hline GRD & 0,06 & 0,56 & 0,35 & 0,52 \\
\hline CTL & 0,33 & 0,12 & 0,29 & 0,24 \\
\hline BTK & 0,17 & 0,26 & 0,22 & 0,16 \\
\hline LN & 0,45 & 0,06 & 0,13 & 0,08 \\
\hline
\end{tabular}

TABEL 9 BOBOT PRIORITAS GLOBAL

\begin{tabular}{|ccccc|}
\hline $\begin{array}{c}\text { Bobot } \\
\text { Prioritas } \\
\text { Global }\end{array}$ & GRD & CTL & BTK & LN \\
\hline & 0,03 & 0,31 & 0,19 & 0,29 \\
\hline & 0,09 & 0,03 & 0,08 & 0,06 \\
\hline & 0,02 & 0,03 & 0,03 & 0,02 \\
\hline & 0,03 & 0,00 & 0,01 & 0,00 \\
\hline jumlah & 0,16 & 0,38 & 0,31 & 0,38 \\
\hline
\end{tabular}

Dari hasil tabel 9, didapatkan LN dan CTL merupakan rangking pertama lalu BTK rangking kedua dan GRD berada di rangking ketiga

\section{KESIMPULAN}

Berdasarkan pembahasan didapatkan kesimpulan sistem pendukung keputusan ini dapat membantu masyarakat dalam memilih maskapai berdasarkan kriteria dan alternatif, tidak kesulitan memilih maskapai penerbangan, serta mengetahui faktor pertimbangan dalam memilih maskapai penerbangan.

\section{SARAN}

Kepada pembaca agar sistem ini dapat dikembangkan dengan maksimal dan bisa diandalkan di masa yang akan datang.

\section{UCAPAN TERIMA KASIH}

Judul untuk ucapan terima kasih dan referensi tidak diberi nomor. Terima kasih disampaikan kepada Tim JTII yang telah meluangkan waktu untuk membuat template ini.

\section{REFERENSI}

[1] Badan Pusat Statistik, "Jumlah Penumpang yang Berangkat pada Penerbangan Domestik di Bandara Utama Indonesia, 2006-2019 (Orang)," Badan Pusat Statistik, 2019. [Online]. Available: https://www.bps.go.id/linkTableDinamis/view/id/812. [Accessed: 25-Dec-2019].

[2] T. R. Adianto, Z. Arifin, D. M. Khairina, G. Mahakam, and G. Palm, "Di Perumahan Menggunakan Metode Simple Additive Weighting ( Saw ) ( Studi Kasus : Kota Samarinda )," Pros. Semin. Ilmu Komput. dan Teknol. Inf., vol. 2, no. 1, pp. 197-201, 2017.

[3] D. N. Kirom, Y. Bilfaqih, and R. Effendie, "Sistem Informasi Manajemen Beasiswa ITS Berbasis Sistem Pendukung Keputusan Menggunakan Analytical Hierarchy Process," J. Tek. ITS, vol. 1, no. 1, pp. 1-6, 2012.

[4] Kusrini, Konsep dan Aplikasi Sistem Pendukung Keputusan. Andi, Yogyakarta, 2007. 